\title{
Social Electrical Engineering A Pathway for Better Undergraduate Education
}

\author{
Amilton da Costa Lamas* \\ *Department of Electrical Engineering, Pontifícia Universidade Católica de Campinas, \\ Campinas,São Paulo, Brazil. \\ E-mail: amilton@puc-campinas.edu.br. \\ Anderson Gomes Domingues* \\ •Department of Electrical Engineering, Pontifícia Universidade Católica de Campinas, \\ Campinas, São Paulo, Brazil. \\ E-mail: dersongd@gmail.com
}

\begin{abstract}
The 21st century Engineers are expected to have a strong technical background while being capable to work with people with different kinds of intellectual and social capitals, and to have a high level of cognitive flexibility. Society's problems are getting harder, broader, and deeper and are multidisciplinary in nature. They require a multidisciplinary systems approach to solve them and present-day Engineering Education is not adequately preparing young Engineers for the challenge. This article reports on the application of an information appropriation method, adopted by the Department of Electrical Engineering at Pontifícia Universidade Católica de Campinas(PUCCampinas), where activities of extension projects are simultaneously conducted along with the regularly schedule classes. The study case is related to the coplanning and cocreation of a technological white cane (proof of connect) between Electrical Engineering students, social technicians and the visually impaired. In the present case, the technicians were led to reinterpret, adapt and reinvent technology while contributing to the design and build of a low cost adaptive electronic sensing aid attachable to a white cane. The collaborative method, applied during conversation rounds, is based on a virtuous cyclic process which includes steps like information capture, validation, guidance
\end{abstract}


14 ISSN: 2358-1271. Int. J. of Alive Eng. Educ. (IJAEEdu). (Online). Goiânia, v. 5, n. 1, p. 13-20, Jan./June 2018.

and feedback. The Engineering students, on the other hand, have the opportunity to develop their communication, analysis and interpretation skills in a way not available in the classroom. They also experience solving conflict situations and find creative uses and applications for they knowledge not otherwise foreseen. The participating students transformed information into knowledge through a dialogical experience with people having a contrasting technological background to their own. Through this experience the Engineering graduates emerged with a greater sense of responsibility with the Society and a better understanding of what means to be an Engineer. Participation in the Extension Project also brought up several opportunities of professional recognition by the technicians and the visual impaired themselves, which stimulated the students do achieve better performance in the course.

Keywords: Collaborative Education, Electrical Engineering, Extension Projects, Visually Impaired, Engineering Education.

\section{Background}

Engineering graduates are entering a world where the scale of professional challenges is enormous and our classical educational system does not address this issue by focusing in preparing students to outperform in exams and assessments ${ }^{1}$. The creativity and innovative capabilities of Engineers are essential for the operation and Society advancement. To be competitive and take the role of leadership in the future, the students must have a strong technical background and simultaneously understand their ethical and professional responsibilities towards the well-being of the communities and the nation itself. Many authors ${ }^{2-5}$ agree that the Engineers of 2020 are supposed to be persuasive in multiple social contexts, to be fluent in working with different kinds of intellectual and social capitals, and to have a high level of cognitive flexibility. Furthermore, a few issues regarding Engineering Education have been pointed out by Beanland ${ }^{6}$ :

"a) employers are dissatisfied with the capabilities of many graduate Engineering graduates, b) educational curriculums off the Universities are overloaded with specialised technical detail as a consequence of the technology explosion, c) work experience is valued and important, but uncommon and d) the abilities to evaluate, to be creative, to identify what is relevant, to learn as it is necessary, and to apply this learning responsibly and efficiently, are not adequately addressed".

All these demands are scarcely addressed by the majority of undergraduate Engineering schools. The academic world needs to foster Higher Education students able to develop collaborative solutions and capable of appropriating knowledge from different sources. Major industries stated the need for Engineers with deep knowledge and expertise in their discipline, combined with a broad extent of cross disciplinary knowledge having an understanding of human as well as social aspects of Engineering, communication, and being able to pursue coplanning, and cocreation in collaborative problem solving. Collaborative problem solving is "the capacity of an individual to effectively engage in a process whereby two or more agents attempt to solve (or work in) a problem by sharing the understanding and effort required to coma to a solution and pooling their knowledge, skills and efforts to reach that solution"7.

Collaborative problem solving engage individuals in cognitive processing to understand and solve problem situations where a process of solution is not immediately obvious. It is essentially a social collaborative process where is important to establish a joint understanding of the problem and then devise a way to the solution, through processes of interthinking and argumentation. It is clear that collaborative problem solving is more than an individual problem solving in the company of others, it requires a set of sophisticated interaction skills, 
used at the same time to support the thinking of others, to coordinate their thinking with one's own, and to achieve a mutually agreed goal.

Few students are exposed to high quality collaborative problem-solving, and few receive training in the cognitive and social skills required for it. The ability to understand something sufficiently to satisfy standardised assessments is no longer enough. Engineering undergraduate students need to be exposed to situations where they must not only be able to explain, synthetize with the knowledge of others, justify and revise their understanding, and apply their knowledge to solve problems.

\section{Purpose/Hypothesis}

The above scenario motivated the development of a non-classical academic experience where not only the technical aspects are deeply addressed, but new opportunities to improve creativity of the Electrical Engineering graduate emerges. The purpose of this paper is to report on a pedagogical strategy adopted by the Department of Electrical Engineering at PUC-Campinas, where activities on extension projects are simultaneously conducted along with the regularly schedule classes as a way to better prepare the students for the market. The study case is related to the knowledge and information exchange between Electrical Engineering students and laypeople (social technicians) dealing with the visually impaired. The goal is to cocriate an inexpensive and versatile technological white cane capable to detect obstacles above floor level, therefore promoting safe independent mobility.

The activities here described were conducted with the participation of two partners institutions, the Sociedade Campinas de Atendimento ao Deficiente Visual (PRÓ-VISÃO) and the Centro Cultural Louis Braille de Campinas (CCLBC). Both institutions provide assistance for the underprivileged visually impaired living in Campinas, São Paulo, Brazil and vicinities.

\section{Design/Method}

The extension project where the activities were conducted aims to promote the autonomous mobility of the visually impaired by exerting the Electrical Engineering technology appropriation by the partners institutions. Technology appropriation in this paper does not mean pure solution replication but involves technology reinterpretation, adaptation and reinvention, which presumes change in semantic association, use and structure. In order to do so it was devised a collaborative method where the participants are: 1) engaged in a coordinated, continuing attempt to solve a problem and construct common knowledge; 2) involved in a coordinated joint commitment to a shared goal, reciprocity, and continual (re-)negotiation of meaning; 3) establishing and maintaining intersubjectivity or recognition that they have a shared understanding about their endeavour; and 4) engaging in interthinking (thinking together).

The collaborative method applied in this case study makes use of informal conversation rounds, carried out during the execution of a virtuous dialogical cycle. The cycling process, named Information Appropriation Method (IAM), includes steps like information capture, development, validation, guidance, appropriation and feedback. Figure 1, bellow, shows a schematic representation of the Virtuous Dialogical Cycle(VDC).

Normally step of the virtuous dialogical cycle takes one informal conversation round to be completed but, eventually during a project fast paced phase, a full cycle can be performed during a single conversation round. The development step has its own process called Solution Development Process (SDP). SDP is composed by four phases: Conception, 
Elaboration, Construction and Transfering. Figure 2 shows a schematic representation of the SDP.

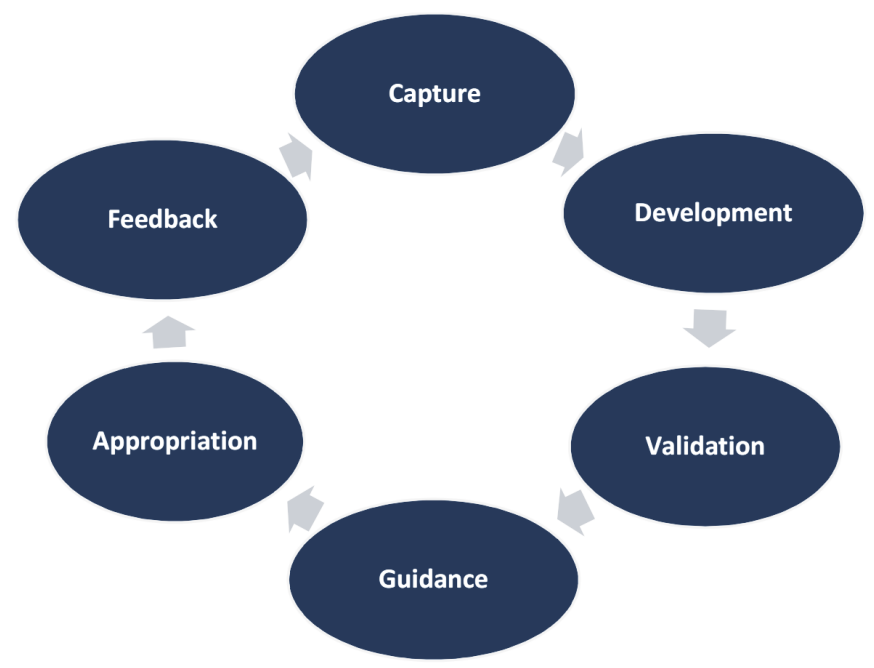

Figure 1. Virtuous Dialogical Cycle(VDC).

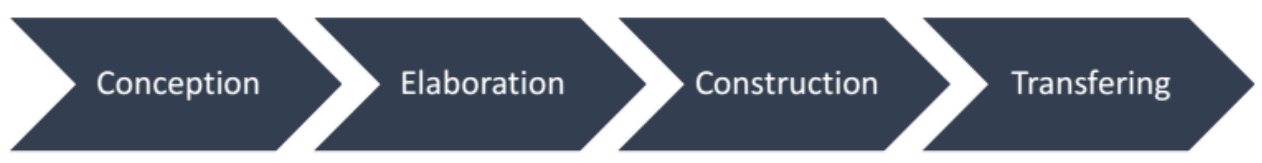

Figure 2. Solution Development Process(SDP).

A detailed description of this model can be found in ${ }^{8}$.

In the present case, the social technicians (target audience) were led to reinterpret, adapt and reinvent technology while contributing to the design and build a proof of concept of a low cost adaptive electronic sensing aid attachable to a white cane. The Electrical Engineering students, on the other hand, have the opportunity to develop their communication, analysis and interpretation skills in a way not available in the classroom. They also experience solving conflict situations and find creative uses and applications for they knowledge not otherwise foreseen. A detailed description of this model can be found in ${ }^{9}$.

\section{Results}

During the extension project execution about 36 informal conversation rounds were conducted at the partner's premises. The first challenge faced by the Engineering students was to conquer the target audience trust and confidence avoiding simultaneously being placed in position of solution provider with Higher Education. To overcame such difficulties the students adopted a non-technical language and focused in developing a reciprocity relationship with the visually impaired and the social technicians. Upon surpassing this initial difficulty, the collaborative grounds where established and the cocreation process started. Defining the functional and non-functional requirements called for two different strategies 
since the visually impaired supported by PRÓ-VISÃO were young, in their early twenties at the most, at CCLBC they were much older, having different needs for autonomous navigation. This diversity resulted on some divergent requirements, demanding creativity from the students when proposing a single solution for both partners. At the end of the capture and development phases the work team (students, social technicians and the visually impaired) agreed upon the following basic requirements for the device: a) should be tested on a white cane, b) should cost less than a regular white cane, c) should be flexible enough to be easily attached to different objects, d) be adjustable for different heights, e) have sound and multimodal haptic feedback, and e) have selectable hazard detection sensitivity. This set of requirements demanded the students to look for innovative solutions not commonly addressed during regular Engineering classes, otherwise the target audience would be unable to appropriate themselves from the solution. Attending to these requirements challenged the student to be integrative and conceptual on its project specially concerning human-centred design.

Communication was a big challenge due to team diversity. While the academic members could fully understand Electrical Engineering terms these were completely unfamiliar to the social technicians, having no meaning whatsoever to them. Development of a common language required the student to move away from its regular way of expressing himself and develop a new non-technical vocabulary to describe technicalities. To overcame this challenge the student had to completely remodel his mindset especially due to the cognitive capabilities diversity of the teammates.

This case study resulted on the cocreation, involving Electrical Engineering students and social technicians, of an electronic mapping device attachable to any object. The mapping device is based on ultrasound emission and was codeveloped with social technician of the partners institutions. The device when attached to a white cane increases above the floor the area allowing for head level obstacle detection, a common source of injury for the visually impaired. The efficiency of the proof of concept so cocreated was verified by placing new obstacles inside and outside the institutions.

Figure 3, bellow, shows the electronic controller architecture, encompassed by a buzzer, on/off button, microcontroller (Arduino), power supply, vibrating motor, and the ultrasonic sensors, located at the tip of the white cane.

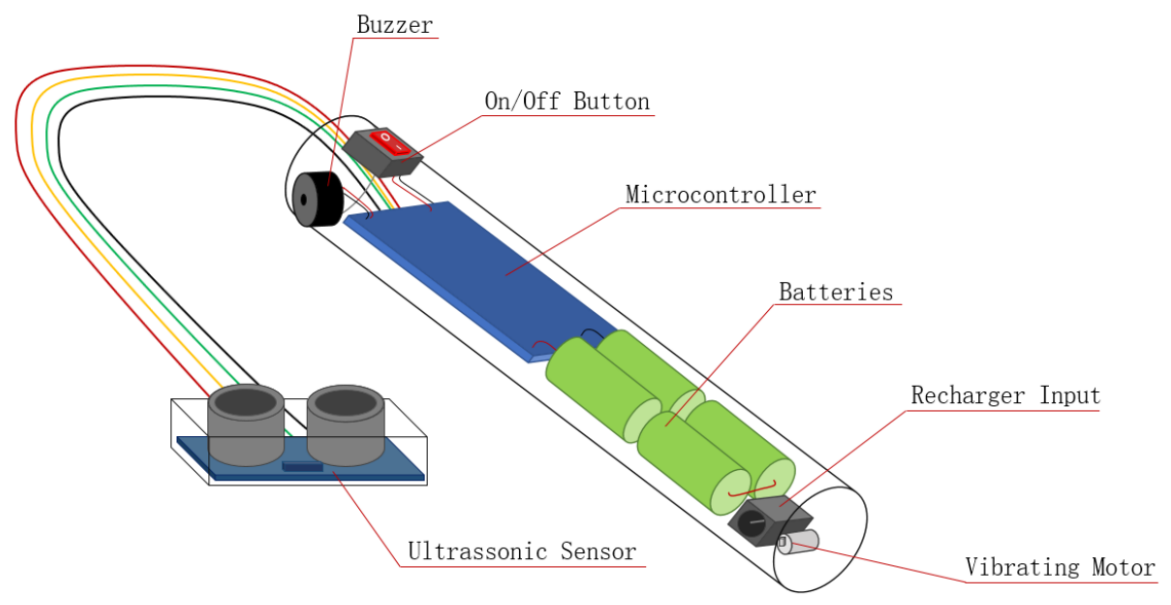

Figure 3. Electronic controller architecture. 
Photographs 1 and 2, below, shows a detail of the electronic controller and a visually impaired social technician experimenting the proof of concept during an informal gathering, respectively.

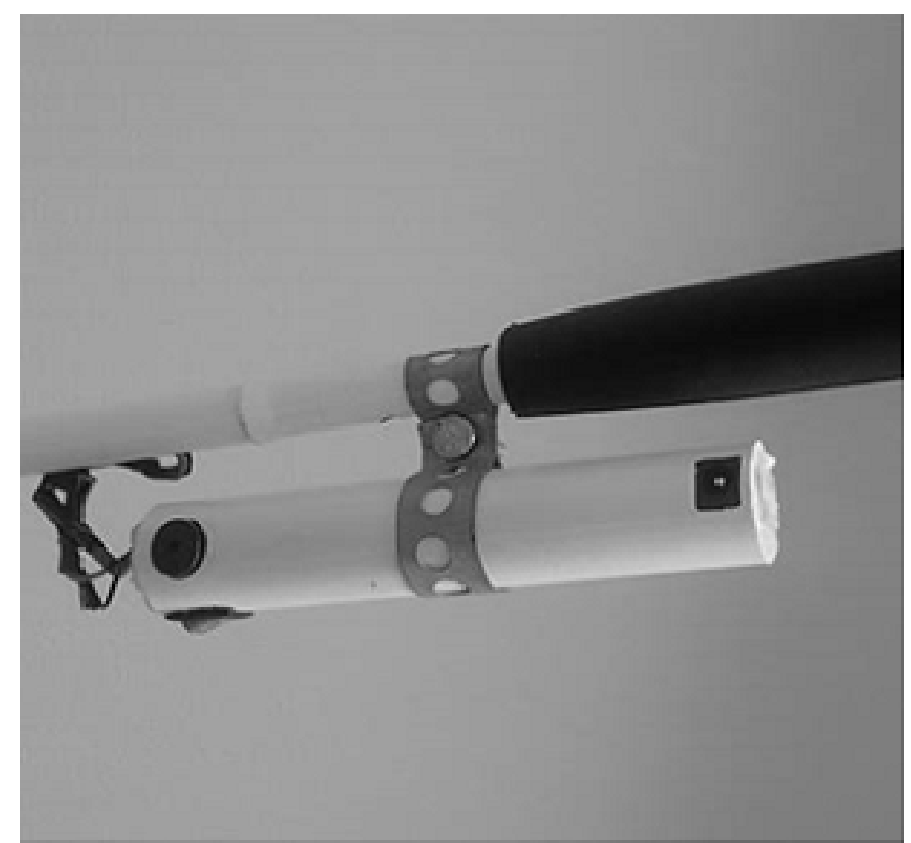

Photograph 1. Detail of the electronic controller. ${ }^{10}$

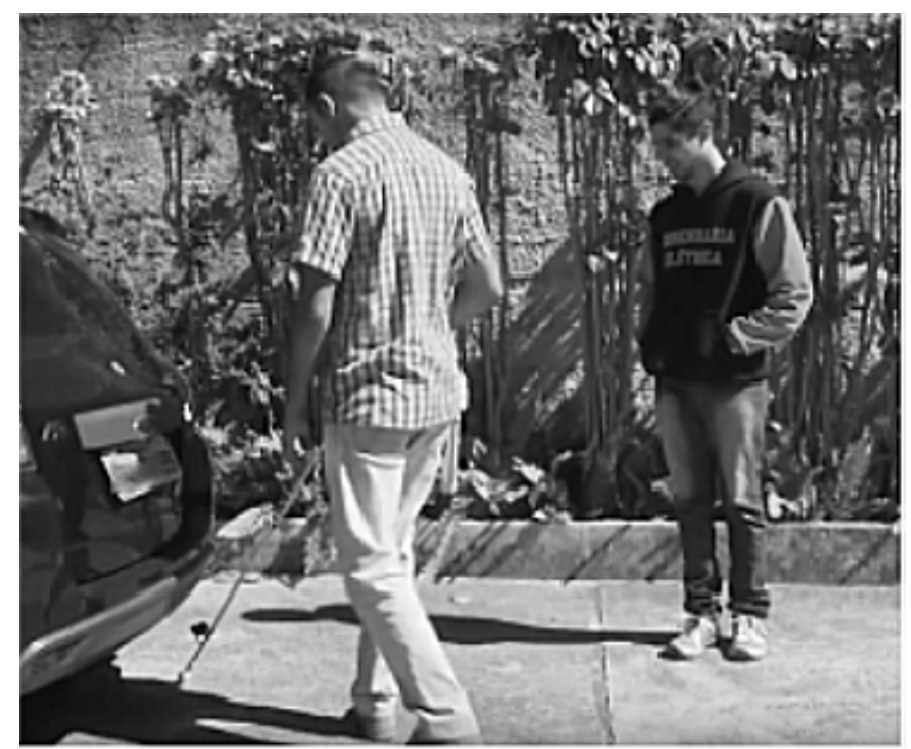

Photograph 2. Social technician using the technological white cane. ${ }^{10}$

The visually impaired expressed unanimously that the white cane attended their expec- 
tations in detecting obstacles, promoting a safer navigation. A complete technical description of the electronic device can be found $i^{8}$. A video presentation of the mapping device can be found $\mathrm{in}^{11}$.

\section{Conclusions}

The study case reported in this paper described the successful coplaning and implementation of an electronic white cane carried out during a university extension project. The employed method allowed the student do experience technical and non-technical knowledge exchange with people with different culture backgrounds. By participating in the project the undergraduate students were able to develop the skills and competences expect by the market for the 21st century Engineers, like critical thinking and integrate human values and business into technical concepts.

During the execution of the presented method Electrical Engineering students were able to develop communication skills and promote their ability to work with anyone, anywhere. The participating students also transformed information into knowledge through a dialogical experience with people having a contrasting technological background to its own. Participation on the project allowed the students to gain hands-on field experience in a challenge driven environment where they face problems for which there are no established answers.

The authors would like to thank the Sociedade Campinas de Atendimento ao Deficiente Visual (PRÓ-VISÃO) and the Centro Cultural Louis Braille de Campinas (CCLBC), for their partnership.

\section{Reference}

1. LUCKIN, R. et al. Solved! Making the case for collaborative problem-solving.NESTA, National Endowment for Science, Technology and the Arts, March 2017. Available in: $<$ http://www.nesta.org.uk/publications/solved-making-case-collaborative-problem-solving $>$. Accessed on: 4 June 2018.

2. MORELL, L. Engineering Education in the 21st Century: Roles, Opportunities and Challenges In: NEA ICETE, 4., 2010, Taichung. Proceedings... Taichung, Taiwan, October 2010.

3. MOHD-YUSOF, K. et al. Future Directions in Engineering Education: Educating Engineers of the 21st Century ASEAN Journal of Engineering Education, 2(1), pp 8-13, 2015. Available in: <http://tree.utm.my/wp-content/uploads/2015/04/AJEE-2014-0022-Typeset.pdf $>$. Accessed on: 4 June 2018.

4. CRADDOCK, D. Preparing Students for de 21st Century Challenges. Available in: $<$ https://www.ewb-uk.org/complexproblemsineducation/>. Accessed on: 4 June 2018.

5. WORLD ECONOMIC FORUM. Global Challenge Insight Report: The future of jobs, employment, skills and workforce strategy for the fourth industrial revolution. [online]. Geneva: World Economic Forum. Available in: $<$ http://www3.weforum.org/docs/WEF_Future_of_Jobs.pdf $>$. Accessed on: 4 June 2018

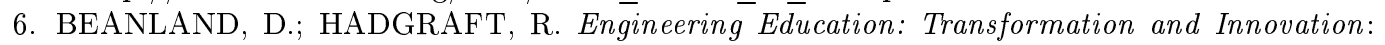
UNESCO Report, 2013.

7. OECD. Draft Collaborative Problem-Solving Framework. Available in: $<$ http://www.oecd.org/pisa/pisaproducts/Draft \%20PISA \%202015 \%20Collaborative \%20Problem \%20Solving \%20Framework \%20.pdf >. Accessed on: 4 June 2018.

8. DOMInGUES, A.; LAMAS, A. Dispositivo Eletrônico de Mapeamento - uso em Bengala Branca In: CONGRESSO BRASILEIRO DE EDUCAÇÃO EM ENGENHARIA - COBENGE, 45. 2017, Joinville. Proceedings..., Joinville, 2017. 
9. LAMAS, A. Método Cíclico de Apropriação de Conhecimento - Uma aplicação na Comunidade de Deficientes Visuais. In: CONGRESSO INTERNACIONAL DE CRIATIVIDADE E INOVAÇÃO, 2., 2017, Campinas. Proceedings..., Campinas, June 2017.

10. LAMAS, A. C.; DOMINGUES, A. G. Electrical Engineering Graduates and Extension Projects: A White Cane Collaborative Development Case Study In: DEUS JUNIOR, G. A. de et. al. (Org.). Alive Engineering Education Transforming and Innovating Engineering Education. Goiania: Cegraf UFG, 2017. cap. 10, p. 121-130. Available: <https://icaeedu.emc.ufg.br/p/22211-alive-engineering-educationtransforming-andinnovating-engineering-education $>$. Accessed on: 7 Jun. 2018.

11. TV PUC CAMPINAS. Aluno da PUC-Campinas desenvolve bengala eletrônica para cegos. 2016. Available in: <https://www.youtube.com/watch?v $=$ wAWuG-PdtX0 $>$. Accessed on: 4 June 2018 